\title{
The influence of preoperative anemia on one-year mortality after orthotopic liver transplantation
}

Paul Lichtenegger ${ }^{1}$, Judith Schiefer ${ }^{1}$, Alexandra Graf², Gabriela Berlakovich ${ }^{3}$, David M. Baron ${ }^{1}$, Joanna Baron ${ }^{1}$

1 Department of Anaesthesia, Intensive Care Medicine and Pain Medicine, Medical University of Vienna, Austria

2 Section for Medical Statistics, Center for Medical Statistics, Informatics, and Intelligent Systems, Medical University of Vienna, Austria 3 Department of Surgery, Division of Transplantation, Medical University of Vienna, Austria

\section{BACKGROUND}

Anemia is a common condition in end-stage liver disease (1). In previous studies, preoperative anemia was associated with greater mortality after major surgery $(2,3)$. The aim of this study was to investigate the influence of preoperative anemia on one-year mortality after orthotopic liver transplantation (OLT).

\section{METHODS}

This single-center retrospective study was performed at the Medical University of Vienna after local ethics committee approval. Patients undergoing their first OLT between 2004 and 2016 were included. Exclusion criteria were combined liver-kidneytransplantation and combined liver-lungtransplantation. Anemia was defined according to the classification of the WHO. Hemoglobin values were determined within 24 hours prior to surgery. In this preliminary analysis to assess one-year mortality, a univariate cox regression model for death as event accounting for the combined factor of anemia (mild, moderate, and severe) was calculated.

\section{RESULTS}

We included 607 patients with a mean age of $53 \pm 8$ years (non-anemic patients $55 \pm 8$ years, anemic patients $53 \pm 10$ years, $P=0.01$ ). Preoperatively, $24 \%(n=146)$ of patients had no anemia, while $76 \%(n=461)$ of patients suffered from anemia.

References:

1. Stein J, et al. World J Gastroenterol. 2016;22(35):7908-25.

2. Baron DM, et al. Br J Anaesth. 2014;113(3):416-23.

3. Musallam KM, et al. Lancet $2011 ; 378(9800): 1396-407$

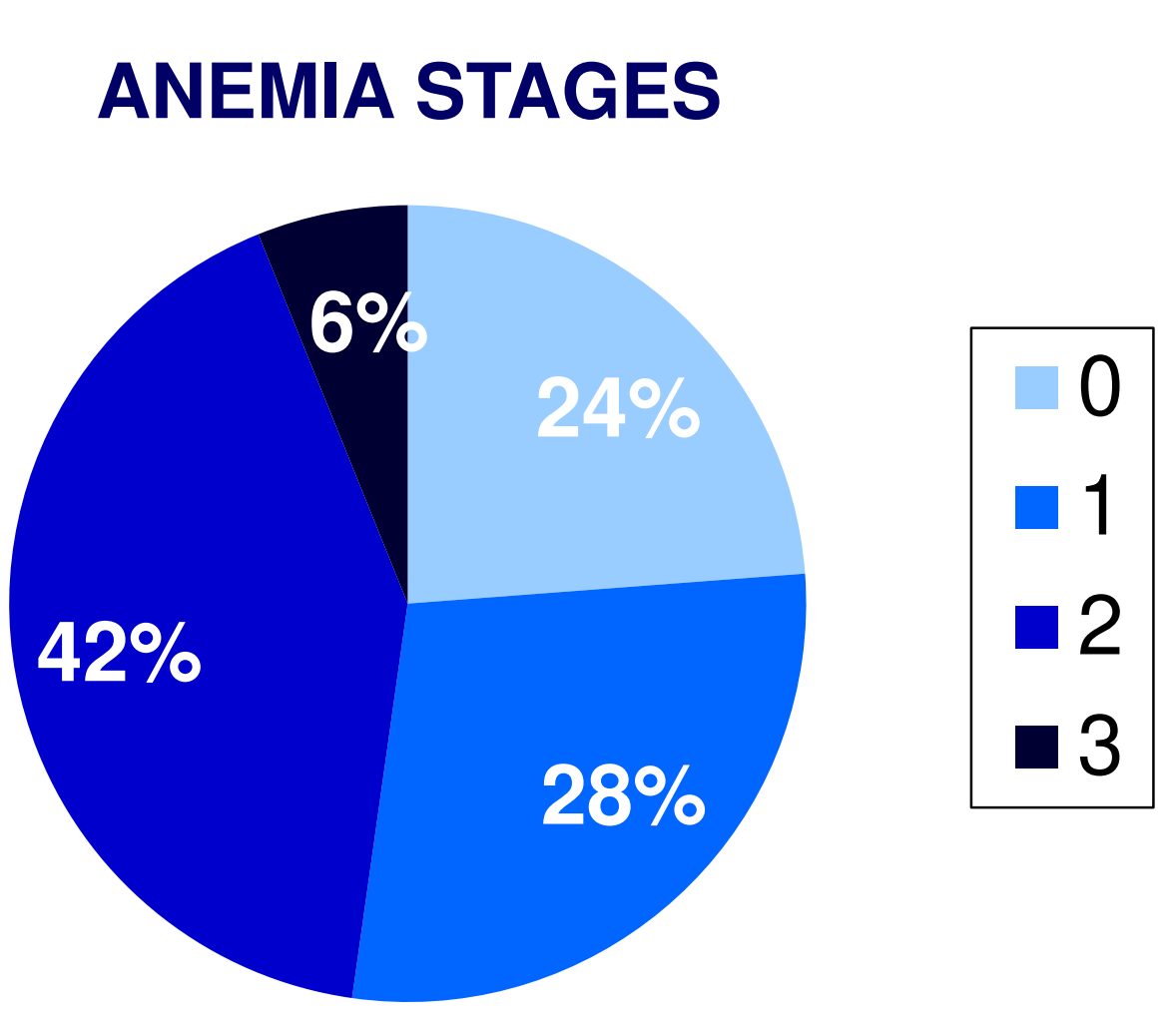

One-year mortality after OLT did not differ between preoperatively non-anemic ( $21 \%$ mortality) and anemic patients (21\% mortality). Non-anemic patients required less intraoperative transfusion of red blood cell units than anemic patients $(2 \pm 3$ versus $4 \pm 5$ units, respectively, $\mathrm{P}<0.001)$.

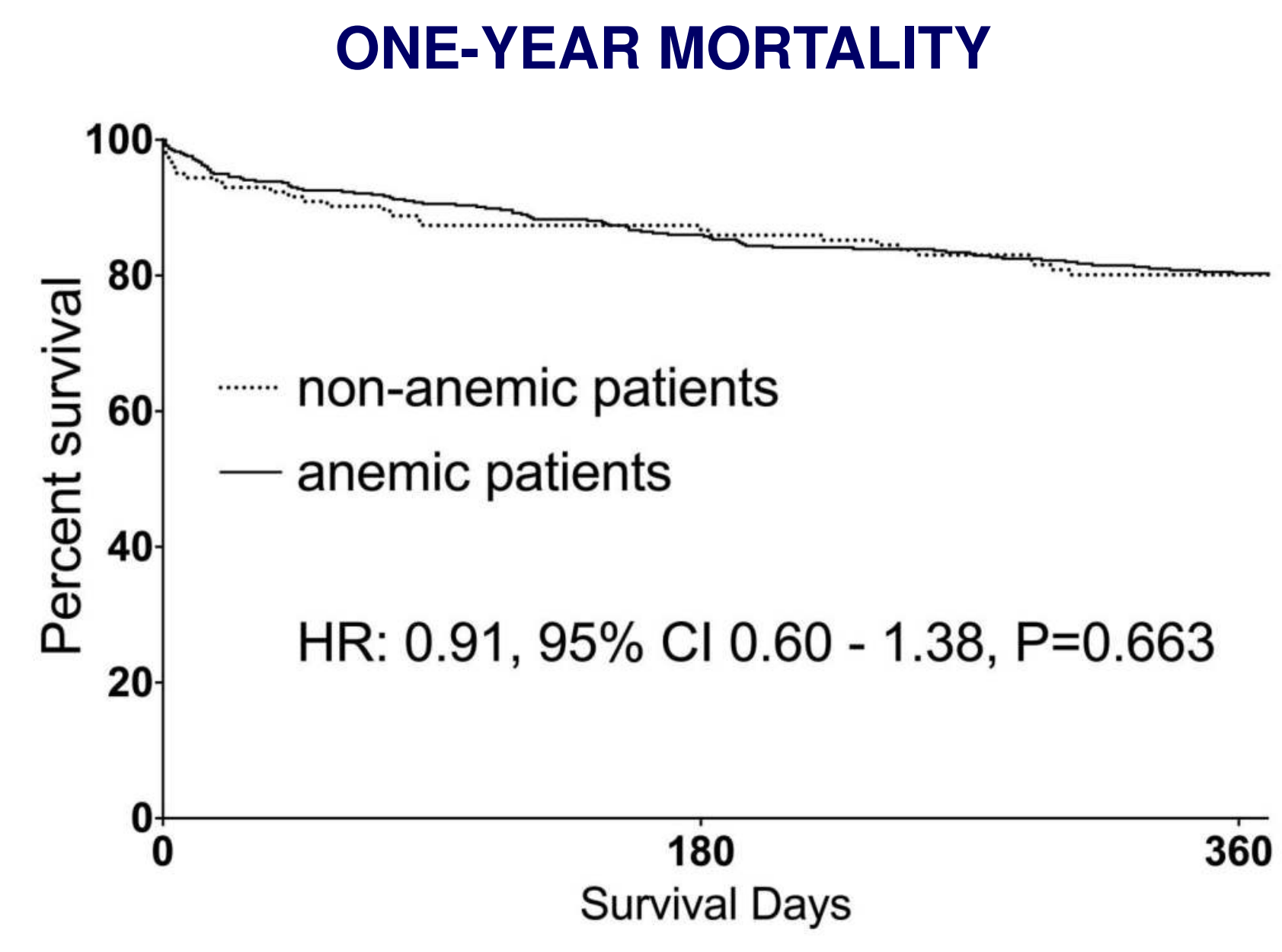

\section{CONCLUSION}

This retrospective study suggests that preoperative anemia does not affect one-year mortality but is associated with increased intraoperative transfusion of red blood cell units in patients undergoing their first OLT. 